\title{
Eficácia Comunicacional dos Docentes do Ensino Superior: Evidência Confirmatória do Construto
}

\author{
Arménio Rego ${ }^{1}$ \\ Universidade de Aveiro, Portugal
}

\begin{abstract}
Resumo
O artigo expõe evidência confirmatória da dimensionalização dos comportamentos comunicacionais dos professores do ensino superior. 131 professores e 87 estudantes universitários foram convidados a descrever os comportamentos de um antigo docente e a atribuírem-lhe uma cotação global de eficácia comunicacional. Os principais resultados são: a) a tetra-dimensionalização (comportamento empático, conscienciosidade, cortesia e (não) leitura exclusiva de textos) ajusta-se satisfatoriamente aos dados, embora alguns elementos sugiram que a primeira dimensão seja dividida em duas (comportamento apoiante; facilitação comunicacional); b) as cinco dimensões explicam cerca de $80 \%$ de variância da cotação de eficácia comunicacional; c) os estudantes e os professores inquiridos valorizam fortemente as cinco dimensões comunicacionais, embora os professores valorizem mais a conscienciosidade, e os estudantes as duas dimensões empáticas. Genericamente, o instrumento revela boas propriedades psicométricas e aponta caminhos de investigação potencialmente frutuosos para o fomento da qualidade no ensino superior.

Palavras-chave: Qualidade no ensino superior; eficácia comunicacional dos professores universitários.
\end{abstract}

\section{Communication Effectiveness of University Teachers: Confirmatory Evidence of the Construct}

\begin{abstract}
This paper aims at showing confirmatory evidence of the instrument for measuring communication effectiveness of university teachers. 131 university teachers and 87 students described the behaviors of a former teacher, and gave him/her a global score for communication effectiveness. The findings are as follow: a) the four factor model (empathetic behavior; pedagogical conscientiousness; courtesy; "just reading of the texts") fits well the data, although it seems more desirable to divide the first factor into two dimensions (supporting behavior, communication facilitation); b) the five dimensions explain about $80 \%$ of the global effectiveness score; c) both students and teachers value greatly all behaviors, although empathetic behavior is more valued by students than by teachers, with the latter valuing the pedagogical conscientiousness more. In general, the instrument reveals good psychometric properties and highlights some avenues for future research in the domain of quality in higher education.

Keywords: Quality in higher education; communication effectiveness in the classroom.
\end{abstract}

O que significa ser um docente comunicacionalmente eficaz? Quais os comportamentos determinantes da eficácia comunicacional dos docentes do ensino superior? Destas interrogações não podem esperar-se respostas exaustivas e/ou universais e/ou unívocas. É possível, no entanto, descortinar algumas tentativas de resposta em diversa literatura atinente à qualidade do ensino superior (v.g., Ellington \& Ross, 1994; Helms \& Key, 1994; Horsburgh, 1999; Marsh, Hau, Chung \& Siu, 1998; Rowley, 1996; Stringer \& Irwing, 1998). A título ilustrativo, podem citar-se o feedback da aprendizagem pontual e justo, entusiasmo e dinamismo, espírito de diálogo e práticas reflexivas partilhadas, atuação amistosa do docente, humor na apresentação das matérias, encorajamento da discussão, aulas estimulantes e desafiantes, preparação dos materiais de leccionação, clareza das explicações.

\footnotetext{
${ }^{1}$ Endereço para correspondência: Campus Universitário de Santiago, 3810-193, Aveiro, Portugal. Fone: (351) 234370024, Fax: (351) 234370215. E-mail: arego@egi.ua.pt
}

Sucede que muitos progressos, no campo científico, implicam a existência de instrumentos de medição psicometricamente válidos. Se pretendermos identificar as categorias comunicacionais relevantes para a eficácia dos docentes do ensino superior, e se desejamos conhecer os efeitos que os respectivos comportamentos exercem sobre os estudantes, é fundamental que dispunhamos de ferramentas de medição que, pelos seus atributos psicométricos, nos ofereçam algumas garantias de validade dos resultados empíricos. Só assim, aliás, se pode acalentar a esperança de identificar áreas de atuação no terreno sobre as quais... "vale a pena" intervir.

Com esse fito, Rego e Sousa (1998a, 1998b, 2000b) realizaram pesquisa empírica exploratória, recorrendo à técnica dos incidentes críticos (Flanagan, 1954). Inquirindo uma amostra de 196 estudantes universitários (que descreveram 350 incidentes), identificaram 19 categorias potencialmente conducentes à (in)eficácia comunicacional dos docentes deste nível de ensino. O esboço traçado por essa pesquisa permitiu a Rego (2000) elaborar, 
desenvolver e validar um questionário composto por 23 itens. A aplicação da análise fatorial das componentes principais aos dados recolhidos numa amostra constituída por 132 estudantes (que se debruçaram sobre os comportamentos de actuais professores) e 69 docentes universitários (que refletiram sobre os seus antigos mestres) sugeriu a existência de quatro categorias comunicacionais, a seguir expostas.

O comportamento empático (10 itens; alpha: 0,92) incorpora atos comunicacionais de proximidade, participação e empenho, simplicidade e atratividade da linguagem, e apoio socioafetivo. A conscienciosidade pedagógica (6 itens; 0,85 ) integra comportamentos atinentes à preparação da aula, sua estruturação e organização, e competência "técnica". A (des)cortesia" (5 itens; 0,87 ) respeita à (in)delicadeza e grau de (des)respeito no tratamento dos estudantes. A quarta dimensão respeita à leccionação com base (ou não) na leitura exclusiva de textos (2 itens; 0,89 ).

Estas quatro dimensões (com especial destaque para o comportamento empático e a conscienciosidade pedagógica) explicam cerca de $80 \%$ da variância de uma notação global de eficácia comunicacional atribuída pelos inquiridos aos docentes sobre os quais se exprimiram. $\mathrm{E}$ essa tendência revelou-se extensiva aos dois tipos de inquiridos. Ou seja: tanto os professores como os estudantes revelaram concepções bastante convergentes no que concerne ao papel desses comportamentos na eficácia comunicacional docente.

Pese embora o otimismo que pode ser projetado sobre esta ferramenta, o estudo que a sustenta contém algumas limitações. Por exemplo, os inquiridos foram recolhidos numa só instituição universitária. Não foram inquiridos participantes oriundos de instituições politécnicas. Ademais, a última dimensão comunicacional atrás mencionada foi medida através de, apenas, dois itens. Esta situação é indesejável quando se pretende efetuar análises fatoriais confirmatórias (Byrne, 1998; Joreskog \& Sorbom, 1993), pois é recomendável o recurso a, pelo menos, três descritores. Finalmente, a primeira dimensão foi saturada por itens cujo conteúdo é, pelo menos aparentemente, algo fluido. Esta situação pode advir das particularidades atinentes à técnica da análise fatorial dos componentes principais (Kline, 1994), que tende a congregar no primeiro fator a maior parte das variáveis. Há, por conseguinte, interesse em proceder a averiguações adicionais de validação. A presente pesquisa tem esse fito. Procuraremos mostrar se a estrutura dimensional anteriormente detectada recebe ou não confirmação empírica, e se o seu potencial preditivo da cotação global de eficácia comunicacional se mantém.

\section{Método}

Para o efeito, foi inquirida uma amostra composta por 218 indivíduos. 131 exerciam funções docentes em duas universidades e duas instituições politécnicas portuguesas. Distribuíam-se por todas as categorias da carreira docente. Os restantes eram estudantes na Universidade de Aveiro: 26 freqüentavam um curso de pós-graduação na área da educação, 19 inseriam-se num curso de bacharelato em educação de infância, e 42 eram oriundos de cursos das áreas da gestão, economia e engenharia industrial.

Os alunos foram abordados directa e pessoalmente, tendo a resposta sido devolvida, presencialmente, ao investigador. Os professores foram contactados através de missiva colocada na sua caixa/cacifo de correspondência. A cada docente foi fornecido um sobrescrito de resposta sem franquia, para devolução. Dado que este processo envolveu 400 docentes, a taxa de devolução foi de $32 \%$. Foi usada a mesma estratégia com todos os inquiridos:

a) Foi-lhes solicitado que refletissem sobre um antigo docente à sua escolha.

b) Foram informados de que a opção poderia recair sobre qualquer docente, independentemente do sexo, idade e área disciplinar, de gostarem ou não dele, e de o considerarem ou não competente. A única condição proposta foi que conhecessem bem a forma como ele se comportava em sala de aula.

c) Foi apresentado um questionário contendo os 23 itens remanescentes da análise fatorial obtida por Rego (2000), aos quais foi acrescentado um descritor destinado a medir a última dimensão comunicacional atrás citada. Os 24 itens estão expostos no Anexo A.

d) Foram convidados a assinalar em que grau essas afirmações se aplicavam ao docente sobre o qual refletiam, numa escala de 1 ("não se aplica rigorosamente nada") a 7 ("aplica-se completamente").

e) Para além de lhes terem sido solicitados outros dados que neste artigo não serão considerados, foram ainda convidados a atribuir ao docente escolhido uma cotação global de eficácia comunicacional, numa escala de 0 ("péssimo comunicador") a 20 ("excelente comunicador"). Esta bitola corresponde à que é usada pelos docentes para avaliar os alunos, sendo que a aprovação é alcançada com uma classificação mínima de 9,5.

\section{Resultados}

Os dados comportamentais foram submetidos a uma análise fatorial confirmatória (Byrne, 1998; Joreskog \& Sorbom, 1993), à luz do modelo tetra-fatorial emergente em Rego (2000). Os índices de ajustamento não se

Psicologia: Reflexão e Crítica, 2001, 14(3), pp. 563-569 
revelaram satisfatórios, o que não é surpreendente se atendermos à elevada quantidade de itens. Procedemos, então, à remoção de descritores de acordo com os valores dos índices de modificação e dos resíduos estandardizados. O modelo resultante está exposto na tabela 1, denotando índices de ajustamento bastante satisfatórios. Os coeficientes de consistência interna são superiores a 0,70 (Nunnally, 1978).

Foram posteriormente testados dois modelos alternativos. Num deles, todos os itens foram imputados a um único fator. Os índices de ajustamento revelaram- se insatisfatórios (v.g., RMSEA: 0,163; GFI: 0,68). No outro, atendendo ao conteúdo semântico dos descritores da dimensão "comportamento empático", procedeu-se à sua separação em dois fatores. O primeiro contém três itens, representando o grau em que o professor adota uma postura comunicacional de natureza apoiante. O outro integra quatro descritores cujo conteúdo semântico transparece um espírito facilitador da comunicação. Este modelo denota índices de ajustamento ligeiramente mais satisfatórios do que o modelo tetra-dimensional (Tabela 1). Os Alphas de Cronbach são sempre superiores a 0,70 .

Tabela 1. Análise Fatorial Confirmatória dos Comportamentos Comunicacionais (solução completamente standardizada)

\begin{tabular}{|c|c|c|}
\hline \multicolumn{3}{|c|}{ Modelo tetra-fatorial Modelo penta-fatorial } \\
\hline Comportamento empático & $(0,87)$ & \\
\hline Comportamento apoiante & & $(0,84)$ \\
\hline 1.Facilitava a participação dos alunos no processo de comunicação. & 0,76 & 0,78 \\
\hline 3. Empenhava-se ativamente para que os alunos compreendessem o que ele estava dizendo. & 0,75 & 0,75 \\
\hline 19. Apoiava os alunos no seu processo de aprendizagem em sala de aula. & 0,65 & 0,88 \\
\hline Facilitação da comunicação & & $(0,76)$ \\
\hline 7. Sabia fazer humor quando era necessário. & 0,64 & 0,69 \\
\hline 11. Sabia complementar a exposição oral com linguagem não-verbal (ex: gestual ou corporal). & 0,54 & 0,67 \\
\hline 15. Utilizava uma linguagem simples. & 0,75 & 0,55 \\
\hline 17. Complementava a exposição da matéria com exemplos práticos. & 0,84 & 0,78 \\
\hline Conscienciosidade pedagógica & $(0,86)$ & $(0,86)$ \\
\hline 2. A exposição das matérias era muito confusa (I). & 0,72 & 0,72 \\
\hline $\begin{array}{l}\text { 6. Quando comunicava conosco, percebia-se que sabia do que estava a falar } \\
\text { (isto é, que tinha bons conhecimentos da matéria). }\end{array}$ & 0,68 & 0,68 \\
\hline 10. Através do modo como falava, percebia-se que preparava bem as aulas. & 0,85 & 0,85 \\
\hline 21. As aulas não tinham seqüência lógica (I). & 0,70 & 0,70 \\
\hline 23. Expunha a matéria de modo desorganizado (I). & 0,85 & 0,85 \\
\hline (Des)cortesia & $(0,79)$ & $(0,79)$ \\
\hline 12. Era agressivo no modo como comunicava com os alunos (I). & 0,73 & 0,73 \\
\hline 14. Tratava os alunos como "crianças" (I). & 0,69 & 0,69 \\
\hline 22. Era indelicado no relacionamento com os alunos (I). & 0,83 & 0,83 \\
\hline (Não) leitura exclusiva de textos & $(0,90)$ & $(0,90)$ \\
\hline $\begin{array}{l}\text { 9. Expunha a matéria, exclusivamente, lendo ou ditando (por ex: o livro, } \\
\text { os transparentes, ou algum texto que trazia consigo) (I). }\end{array}$ & 0,90 & 0,90 \\
\hline $\begin{array}{l}\text { 16. Normalmente, apenas lia ou ditava os textos/livros que trazia escritos (I). } \\
\text { 24. Os alunos tinham que passar uma grande parte do tempo da aula a ouvir }\end{array}$ & 0,92 & 0,92 \\
\hline o que ele lia ou ditava $(\mathrm{I}))$ & 0,81 & 0,81 \\
\hline Índices de ajustamento & & \\
\hline Qui-quadrado $(p)$ & $244,66(p=0,0000)$ & $216,86(p=0,0000)$ \\
\hline Qui-quadrado/Graus de liberdade & 1,9 & 1,7 \\
\hline Root mean square error of approximation & 0,064 & 0,058 \\
\hline Goodness of fit index & 0,89 & 0,90 \\
\hline Adjusted goodness of fit index & 0,85 & 0,86 \\
\hline Parsimony goodness of fit index & 0,67 & 0,66 \\
\hline Normed fit index & 0,89 & 0,91 \\
\hline Non-normed fit index & 0,93 & 0,95 \\
\hline Parsimony normed fit index & 0,76 & 0,74 \\
\hline Comparative fit index & 0,94 & 0,96 \\
\hline Incremental fit index & 0,94 & 0,96 \\
\hline Relative fit index & 0,87 & 0,88 \\
\hline Ncrítico & 146,37 & 160,87 \\
\hline
\end{tabular}

(I) A pontuação nestes itens foi invertida. Os valores entre parêntesis representam os Alphas de Cronbach. 
A Tabela 2 expõe os resultados das análises de regressão. Denota o poder explicativo das dimensões comunicacionais para a cotação de eficácia comunicacional global. Os dados mais salientes são de dois tipos. Primeiro: as variâncias explicadas cifram-se em cerca de $80 \%$, quaisquer que sejam a subamostra e a estrutura dimensional consideradas. Segundo: relativamente aos estudantes inquiridos, os professores valorizam mais a (não) leitura exclusiva dos textos e, especialmente, a conscienciosidade pedagógica. O inverso ocorre com o comportamento empático, neste sobressaindo a postura apoiante. os tipos de inquiridos lhes atribuem fraca cotação de eficácia comunicacional global.

c) Os docentes do grupo 3 foram apelidados de "Regulares" por denotarem cotações intermédias em todas as dimensões comunicacionais. A pontuação de eficácia global que receberam dos inquiridos situa-se na fronteira entre a nota "positiva" e a "negativa".

d) O grupo 4 é composto por docentes que designamos "Conscienciosos e corteses". São corteses, preparam e organizam as aulas, não ministram as lições com base na leitura exclusiva de textos - mas são pouco propensos a comportamentos comunicacionais apoiantes e facilitadores.

Tabela 2. Regressões para a Cotação Global de Eficácia Comunicacional

\begin{tabular}{|c|c|c|c|c|c|c|}
\hline & \multicolumn{3}{|c|}{ Modelo tetra-fatorial } & \multicolumn{3}{|c|}{ Modelo penta-fatorial } \\
\hline & $\begin{array}{r}\text { Total } \\
(n=218)\end{array}$ & $\begin{array}{l}\text { Docentes } \\
(n=131)\end{array}$ & $\begin{array}{l}\text { Estudantes } \\
(n=87)\end{array}$ & $\begin{array}{c}\text { Total } \\
(n=218)\end{array}$ & $\begin{array}{l}\text { Docentes } \\
(n=131)\end{array}$ & $\begin{array}{l}\text { Estudantes } \\
(n=87)\end{array}$ \\
\hline Comportamento empático & $0,47 * * *$ & $0,40^{* * *}$ & $0,62^{* * *}$ & & & \\
\hline Comportamento apoiante & & & & $0,25^{* * *}$ & $0,17^{* *}$ & $0,43 * * *$ \\
\hline Facilitação da comunicação & & & & $0,25^{* * *}$ & $0,27 * * *$ & $0,20 *$ \\
\hline Conscienciosidade pedagógica & $0,36 * * *$ & $0,40 * * *$ & $0,27 * * *$ & $0,36 * * *$ & $0,40 * * *$ & $0,30 * * *$ \\
\hline Cortesia & $-0,00$ & 0,03 & $-0,03$ & $-0,01$ & 0,03 & $-0,05$ \\
\hline (Não) leitura exclusiva de textos & $0,22 * * *$ & $0,23 * * *$ & $0,14^{*}$ & $0,22^{* * *}$ & $0,23 * * *$ & $0,15^{*}$ \\
\hline$F$ & $201,60 * * *$ & $110,92 * * *$ & $88,01 * * *$ & $160,66 * * *$ & $88,51 * * *$ & $72,22 * * *$ \\
\hline$R^{2}$ & 0,79 & 0,79 & 0,82 & 0,79 & 0,78 & 0,82 \\
\hline$R^{2}$ ajustado & 0,79 & 0,77 & 0,81 & 0,79 & 0,77 & 0,81 \\
\hline
\end{tabular}

${ }^{*} p<0,05 \quad * * p<0,01 \quad * * * p<0,001$

A Tabela 3 expõe a caracterização de seis agrupamentos docentes. As configurações foram gizadas a partir de análises de clusters e de variância. Primeiro: os docentes escolhidos pelos inquiridos foram agrupados de acordo com as cotações nas cinco dimensões comunicacionais (método: ward; distância: euclidiana ao quadrado). Segundo: foram operadas comparações inter-grupos no que concerne a esses comportamentos e à cotação global de eficácia comunicacional. As designações e caracterização dos grupos são as seguintes:

a) Os docentes do grupo 1 foram denominados "Apenas simpáticos". Expressam fracas cotações nas diversas dimensões comunicacionais, exceto na cortesia. Assemelhase a docentes "simpáticos" mas sem qualidades comunicacionais pertinentes. Tanto os estudantes como os professores inquiridos os consideram muito fracos comunicadores.

b) O grupo 2 recebeu a designação "Fracos comunicadores". Denotam cotações pobres em todas as categorias comunicacionais, especialmente o comportamento apoiante e a facilitação da comunicação. Ambos
Os professores inquiridos consideram-nos bons comunicadores, mas essa concepção não é partilhada pelos estudantes. De acordo, aliás, com a evidência manifestada pelas análises de regressão, é provável que os alunos, relativamente aos professores, sejam mais sensíveis às duas primeiras categorias comunicacionais - o inverso ocorrendo com a conscienciosidade.

e) Os docentes do grupo 5 receberam a denominação de "Bons comunicadores". Denotam elevadas cotações em todas as dimensões comunicacionais, e são considerados bastante eficazes comunicacionalmente por ambos os tipos de inquiridos.

f) Finalmente, o grupo 6 é composto por docentes muito bem cotados em todas as categorias comunicacionais. Foram designados "Excelentes comunicadores", fazendo jus ao facto de ambos os tipos de inquiridos thes concederem uma pontuação global de eficácia comunicacional que ultrapassa os 18 pontos (em 20 possíveis).

\section{Análise, Discussão e Conclusões}

A evidência acabada de expor sugere alguns comentários contributivos da compreensão do instrumento de medição 
Tabela 3. Agrupamentos dos Docentes Escolhidos pelos Inquiridos

\begin{tabular}{|c|c|c|c|c|c|c|c|}
\hline & $\begin{array}{l}\text { Grupo } 1 \\
\text { Apenas } \\
\text { simpáticos } \\
(n=17)\end{array}$ & $\begin{array}{l}\text { Grupo } 2 \\
\text { Fracos } \\
\text { comunicadores } \\
(n=18)\end{array}$ & $\begin{array}{l}\text { Grupo } 3 \\
\text { Regulares } \\
\text { s } \\
(n=19)\end{array}$ & $\begin{array}{l}\text { Grupo } 4 \\
\text { Conscienciosos } \\
\text { e corteses } \\
(n=29)\end{array}$ & $\begin{array}{l}\text { Grupo } 5 \\
\text { Bons } \\
\text { comunicadores } \\
(n=80)\end{array}$ & $\begin{array}{l}\text { Grupo } 6 \\
\text { Excelentes } \\
\text { comunicadores } \\
(n=55)\end{array}$ & $\begin{array}{l}\text { Quantidade } \\
\text { de pares } \\
\text { de grupos } \\
\text { diferentes* }\end{array}$ \\
\hline $\begin{array}{c}\text { Comportamento } \\
\text { de apoio }\end{array}$ & 2,9 & 2,2 & 4,6 & 3,4 & 5,1 & 6,2 & 12 \\
\hline $\begin{array}{l}\text { Facilitação da } \\
\text { comunicação }\end{array}$ & 2,9 & 2,7 & 4,4 & 4,2 & 5,0 & 6,0 & 12 \\
\hline $\begin{array}{c}\text { Conscienciosidade } \\
\text { pedagógica }\end{array}$ & 4,1 & 4,0 & 5,0 & 5,5 & 6,2 & 6,4 & 12 \\
\hline Cortesia & 5,5 & 4,5 & 5,5 & 5,6 & 6,5 & 6,6 & 11 \\
\hline $\begin{array}{l}\text { (Não) lê ou dita } \\
\text { exclusivamente }\end{array}$ & 1,6 & 4,3 & 4,0 & 6,1 & 6,2 & 6,9 & 13 \\
\hline $\begin{array}{l}\text { Média das } 5 \\
\text { dimensões** }\end{array}$ & 3,4 & 3,5 & 4,7 & 5,0 & 5,8 & 6,4 & 13 \\
\hline \multicolumn{8}{|l|}{$\begin{array}{l}\text { Cotação de eficácia } \\
\text { comunicacional }\end{array}$} \\
\hline $\begin{array}{l}\text { Atribuída pelos } \\
\text { docentes }\end{array}$ & 7,9 & 7,0 & 10,0 & 15,2 & 17,1 & 18,3 & 10 \\
\hline $\begin{array}{l}\text { Atribuída pelos } \\
\text { estudantes }\end{array}$ & 6,0 & 6,1 & 11,0 & 11,3 & 16,4 & 18,5 & 11 \\
\hline
\end{tabular}

* Teste Scheffé $(p<0,05) \quad * *$ Alpha de Cronbach $=0,85$

dos comportamentos comunicacionais docentes. Apontemos, em primeiro lugar, para a vertente psicométrica:

a) $O$ instrumento revela boas propriedades psicométricas, seja do ponto de vista do ajustamento do modelo fatorial, da consistência interna das escalas ou do poder preditivo da cotação de eficácia comunicacional.

b) Embora o modelo penta-fatorial denote índices de ajustamento mais favoráveis do que o tetra-fatorial, as diferenças são reduzidas. Além disso, não se descortinam incrementos no poder explicativo para a eficácia global pelo fato de se operar a partição da dimensão empática em duas dimensões. Futuras investigações deverão prosseguir os testes da valia comparativa dos dois esquemas fatoriais: razões de parcimônia psicométrica poderão aconselhar o abandono da partição.

c) Nas pesquisas de Rego (2000), a última dimensão exprimia-se através apenas de dois descritores. Esta situação é indesejável para a realização frutuosa de análises fatoriais confirmatórias, pelo que a presente pesquisa acrescentou um descritor. Esta operação repercute-se positivamente na valia psicométrica do instrumento - aliás visível em dois aspectos. Em primeiro lugar, os lambdas atingem valores bastante elevados. Em segundo lugar, a dimensão expressa razoável poder preditivo da cotação de eficácia comunicacional, o que só muito tenuemente ocorria no estudo de Rego (2000).

Psicologia: Reflexão e Crítica, 2001, 14(3), pp. 563-569
Centremo-nos, agora, nas implicações para a melhoria da comunicação dos docentes do ensino superior. Em primeiro lugar, torna-se claro que os comportamentos investigados são fortemente valorizados pelos docentes e estudantes quando refletem sobre as características dos professores comunicacionalmente eficazes. Esta evidência converge com a exposta por Rego (2000).

Segundo, ambos os tipos de inquiridos valorizam especialmente o comportamento apoiante, a facilitação da comunicação, e a conscienciosidade pedagógica. $\mathrm{Na}$ verdade, a cortesia correlaciona-se positiva e significativamente $(0,55$; para $p<0,000)$ com a eficácia global, mas o seu poder explicativo fica reduzido a zero quando as restantes variáveis são introduzidas na regressão. Ou seja: é uma dimensão que não acrescenta valor preditivo ao já fornecido pelas restantes variáveis. Esta evidência é igualmente consonante com a reportada por Rego (2000). Em suma, tanto os docentes, como os estudantes valorizam fundamentalmente: a) a linguagem simples e atrativa, a ilustração da exposição lectiva com exemplos práticos, a postura participativa, o empenhamento e apoio socioafetivo; b) a preparação das aulas, a organização das mesmas, e a competência no métier.

Terceiro, os professores projetam sobre a conscienciosidade pedagógica um olhar mais penetrante do que os estudantes, o inverso ocorrendo no que concerne 
ao comportamento empático (com especial destaque para a postura apoiante). Esta evidência também é congruente com a anteriormente reportada por Rego (2000). E é igualmente convergente com os dados obtidos por Rego e Sousa (2000a) a propósito dos comportamentos de cidadania docente. É possível que os professores denotem características de personalidade que os induzem a valorizar mais vincadamente o lado técnico-formal da docência. Mas também é presumível que as concepções que projetam sobre os seus antigos mestres sejam condicionadas pela experiência colhida no exercício das mesmas funções profissionais.

Os dados oferecem, por conseguinte, perspectivas promissoras - em dois planos. Em primeiro lugar, expõem episódios comportamentais docentes que, por serem tão consistente e fortemente valorizados por professores e estudantes, são presumivelmente contributivos de melhorias na qualidade do ensino superior. Em segundo lugar, fazem ressaltar as boas propriedades psicométricas do instrumento, assim abrindo caminhos mais seguros para pesquisas futuras. Estas poderão testar a consistência da evidência empírica aqui encontrada. Poderão, aliás, dar passos de maior alcance. Por exemplo:

a) Testando o grau em que o tipo de disciplina pode moderar a relação entre os comportamentos e a eficácia comunicacional. Será que determinadas condutas comunicacionais são mais relevantes para as disciplinas "humanísticas", e outras condutas para as cadeiras "tecnológicas"?

b) Trabalhando com um indicador compósito de eficácia - e não com um simples, como foi o caso da presente pesquisa.

c) Averiguando o contributivo explicativo das dimensões comunicacionais para o sucesso acadêmico dos estudantes, seus níveis de motivação e autoconfiança.

Em suma, o instrumento volta a revelar boas propriedades psicométricas, e sugere vários modos potencialmente capazes de incrementar as melhorias do processo ensino-aprendizagem e, assim, a qualidade no ensino superior. Importa que outros investigadores prossigam os estudos, tendo em vista construir um corpo de conhecimentos empíricos mais sólido.

\section{Referências}

Byrne, B. M. (1998). Structural Equation Modeling with Lisrel, Prelis, and Simplis. London: Lawrence Erlbaum Associates.

Ellington, H. \& Ross, G. (1994). Evaluating teaching quality throughout a university. Quality Assurance in Education, 2(2), 4-9.

Flanagan, J. C. (1954). The critical incident technique. Psychological Bulletin, 51, 327-355.

Helms, S. \& Key, C. H. (1994). Are students more than costumers in the classroom? Quality Progress, September, 97-99.

Horsburgh, M. (1999). Quality monitoring in higher education: The impact on student learning. Quality in Higher Education, 5(1), 9-25.

Joreskog, K. \& Sorbom, D. (1993). Lisrel 8: Structural Equation Modeling with the Simplis Command Language. Hillsdale, NJ: Scientific Software International.

Kline, P. (1994). An easy guide to factor analysis. London: Routledge.

Marsh, H. W., Hau, K., Chung, C. \& Siu, T. L. P. (1998). Confirmatory factor analyses of chinese students' evaluations of university teaching. Structural Equation Modeling, 5(2), 143-164.

Nunnally, J. C. (1978). Psychometric theory (2a. Ed.). New York: McGraw-Hill.

Rego, A. \& Sousa, L. (1998a, Agosto). Communication (in)effectiveness of the university teacher in the classroom. Trabalho apresentado no The $56^{\text {th }}$ Annual Convention of the International Council of Psychologists, Melbourne, Australia.

Rego, A. (2000). Eficácia comunicacional dos docentes universitários operacionalização de um constructo. Psicologia, Educação e Cultura, IV(1), 127-140.

Rego, A. \& Sousa, L. (1998b). Panoramas da Universidade de Aveiro. Aveiro: Editorial da Universidade de Aveiro.

Rego, A. \& Sousa, L. (2000a). Impactos dos comportamentos de cidadania docente sobre os alunos universitários - A perspectiva dos estudantes e dos professores. Linhas Críticas, 6(10), 9-30.

Rego, A. \& Sousa, L. (2000b). Docência universitária: Factores de (in)eficácia comunicacional em sala de aula. Psychologica, 25, 75-87,

Rowley, J. (1996). Measuring quality in higher education. Quality in Higher Education, 2(3), 237-255.

Stringer, M. \& Irwing, P. (1998). Students' evaluations of teaching effectiveness: A structural modeling approach. British Journal of Educational Psychology, 68, 409-426.

Sobre o autor:

Arménio Rego é Licenciado em "Gestão e Administração Pública” pela Universidade Técnica de Lisboa, Mestre em "Ciências Empresariais” pelo Instituto Superior de Ciências do Trabalho e da Empresa (ISCTE-Lisboa), e Doutor em “Organização e Gestão de Empresas” pela mesma Escola. É Professor do Departamento de Economia, Gestão e Engenharia Industrial, na Universidade de Aveiro, Portugal.

Recebido: 08/12/2000

Revisão: 21/06/2000

Aceite Final: 21/06/2001 


\section{Anexo A}

\section{Itens Constantes do Questionário de Medida dos Comportamentos Comunicacionais}

1. Facilitava a participação dos alunos no processo de comunicação.

2. A exposição das matérias era muito confusa.

3. Empenhava-se ativamente para que os alunos compreendessem o que ele estava dizendo.

4. Não sabia do que falava.

5. Expunha a matéria dando exemplos da sua vida pessoal.

6. Quando comunicava conosco percebia-se que sabia do que estava a falar (isto é que tinha bons conhecimentos da matéria).

7. Sabia fazer humor quando era necessário.

8. No modo como falava com os alunos via-se que não tinha consideração por eles.

9. Expunha a matéria exclusivamente lendo ou ditando (por ex: o livro, os transparentes, ou algum texto que trazia consigo).

10. Através do modo como falava percebia-se que preparava bem as aulas.

11. Sabia complementar a exposição oral com linguagem não-verbal (ex: gestual ou corporal).

12. Era agressivo no modo como comunicava com os alunos.

13. Tinha um modo atrativo de falar.

14. Tratava os alunos como "crianças".

15. Utilizava uma linguagem simples.

16. Normalmente apenas lia ou ditava os textos/livros que trazia escritos.

17. Complementava a exposição da matéria com exemplos práticos.

18. Tinha um estilo dinâmico de comunicar.

19. Apoiava os alunos no seu processo de aprendizagem em sala de aula.

20. Discriminava alguns alunos (isto é não os tratava a todos por igual).

21. As aulas não tinham seqüência lógica.

22. Era indelicado no relacionamento com os alunos.

23. Expunha a matéria de modo desorganizado.

24. Os alunos tinham que passar uma grande parte do tempo da aula a ouvir o que ele lia ou ditava. 